\title{
Cascadable Current-Mode First-Order and Second-Order Multifunction Filters Employing Grounded Capacitors
}

\author{
Jiun-Wei Horng, Chun-Li Hou, Ching-Yao Tseng, Ryan Chang, and Dun-Yih Yang \\ Department of Electronic Engineering, Chung Yuan Christian University, Chung-Li 32023, Taiwan \\ Correspondence should be addressed to Jiun-Wei Horng, jwhorng@cycu.edu.tw
}

Received 28 November 2011; Accepted 28 December 2011

Academic Editor: Daisaburo Takashima

Copyright ( $) 2012$ Jiun-Wei Horng et al. This is an open access article distributed under the Creative Commons Attribution License, which permits unrestricted use, distribution, and reproduction in any medium, provided the original work is properly cited.

A configuration for realizing low input and high output impedances current-mode multifunction filters using multiple output second-generation current conveyors (MOCCIIs) is presented. From the proposed circuit configuration, first-order allpass, highpass, lowpass and second-order allpass, notch, bandpass filters can be obtained. The simulation results confirm the theoretical analysis.

\section{Introduction}

Current conveyors (CCs) are receiving much attention for their potential advantages such as inherent wider signal bandwidths, simpler circuitry and larger dynamic range [1, 2]. Current-mode active filters with low input impedance and high output impedance are of great interest because they can be directly connected in cascade to implement higher order filters $[3,4]$. Several current-mode first-order allpass filters using various active components have been reported. Some circuits use two second-generation current conveyors (CCIIs) to realize such a first-order allpass filter function with high output impedance [5]. However, the number of passive components they used are not canonical. Some firstorder circuits use one active component [6, 7]. However, their input impedances are not low. Some first-order circuits use one active element, one capacitor, and one resistor [8-10]. However, these circuits have not the advantage of low input impedance and the capacitors they used are not grounded. In 2007, Metin et al. [11] propose a current-mode first-order allpass filter using two CCIIs, two grounded resistors and one grounded capacitor with low input and high output impedances. In 2009, Lahiri and Chowdhury [12] proposed a current-mode first-order allpass filter using one current differencing transconductance amplifier (CDTA) and one grounded capacitor with low input and high output impedances. As the function of CDTA can also be replaced by two CCII and one operational transconductance amplifier (OTA) [12], if the structure of [12] is constructed by CCIIs and OTA, it requires two CCIIs and one OTA.

In this paper, a new current-mode circuit configuration with low input and high output impedances uses two multiple output second-generation current conveyors (MOCCIIs) is presented. The first-order allpass, highpass, and lowpass filters can be obtained from the proposed circuit configuration.

Several current-mode universal biquadratic filters with single-input and multioutput were presented in the literature [13-15]. However, the input impedances of the circuits in $[13,14]$ are high. Moreover, at least three CCIIs are required in $[14,15]$. Several current-mode universal biquadratic filters with multi-input terminals using current conveyors are presented [16, 17]. However, the input impedances of these circuits are high at most of their input terminals.

In this paper, from the proposed circuit configuration, the second-order allpass, notch, and bandpass filters can also be obtained. All proposed circuits use only grounded capacitors that are attractive for integrated circuit implementation [19]. 


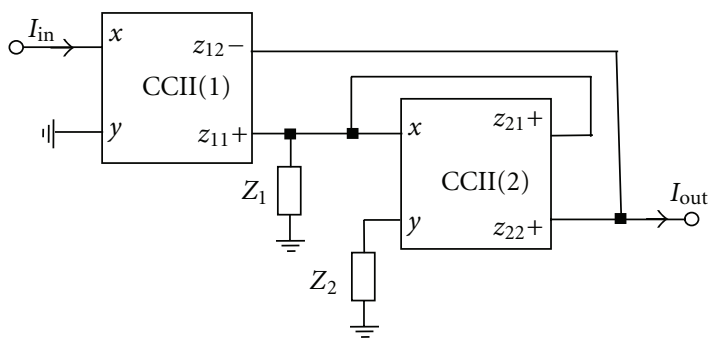

Figure 1: The proposed cascadable current-mode circuit configuration.

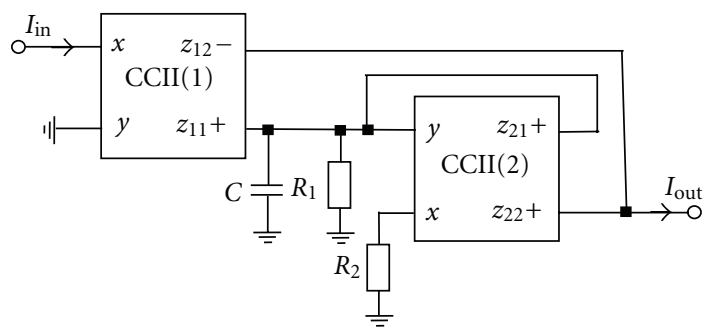

Figure 2: The current-mode first-order filter.

\section{Proposed Circuits}

Using standard notation, the port relations of a MOCCII can be characterized by $v_{x}=v_{y}, i_{z k}= \pm i_{x}$ and $i_{y}=0$. Considering the proposed current-mode circuit in Figure 1, the current transfer function can be expressed as

$$
\frac{I_{\text {out }}}{I_{\text {in }}}=\frac{Z_{2}-2 Z_{1}}{Z_{2}-Z_{1}} .
$$

If the impedances of Figure 1 are taken to be $Z_{1}=R_{1} /(1+$ $\left.s C R_{1}\right)$ and $Z_{2}=R_{2}$, a first-order circuit is obtained as shown in Figure 2. The current transfer function of Figure 2 is

$$
\frac{I_{\text {out }}}{I_{\text {in }}}=\frac{s C R_{1} R_{2}+R_{2}-2 R_{1}}{s C R_{1} R_{2}+R_{2}-R_{1}} .
$$

For $R_{1}=R$ and $R_{2}=1.5 R$, (2) becomes

$$
\frac{I_{\text {out }}}{I_{\text {in }}}=\frac{s-1 /(3 C R)}{s+1 /(3 C R)} \text {. }
$$

This represents a first-order allpass function.

For $R_{1}=R$ and $R_{2}=2 R$, (2) becomes

$$
\frac{I_{\text {out }}}{I_{\text {in }}}=\frac{s}{s+1 /(2 C R)} \text {. }
$$

This represents a first-order highpass function.

In Figure 2, if the $z_{12}-$ output terminal of CCII(1) is eliminated, the transfer function becomes

$$
\frac{I_{\text {out }}}{I_{\text {in }}}=\frac{-R_{1}}{s C R_{1} R_{2}+R_{2}-R_{1}} .
$$

For $R_{1}=R$ and $R_{2}=2 R$, (5) becomes

$$
\frac{I_{\text {out }}}{I_{\text {in }}}=\frac{-1 /(2 R C)}{s+1 /(2 C R)} \text {. }
$$

This represents a first-order lowpass function.

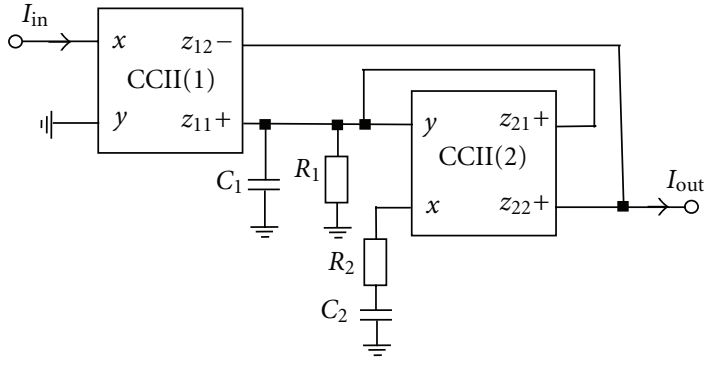

Figure 3: The current-mode second-order filter.

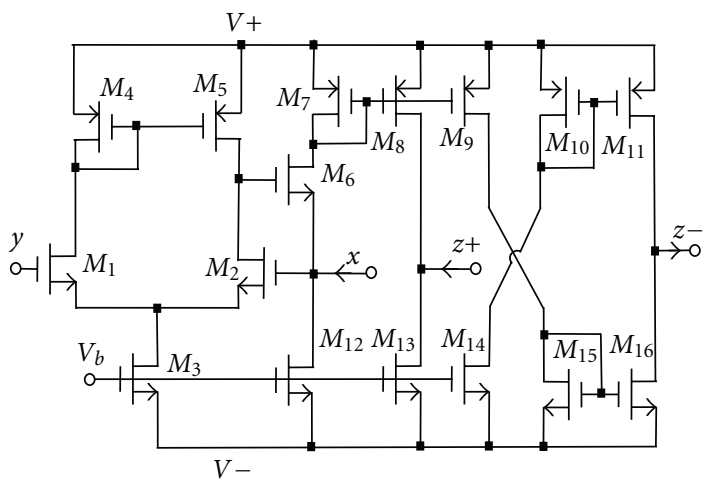

FIgure 4: The CMOS MOCCII implementation.

If the impedances of Figure 1 are taken to be $Z_{1}=R_{1} /(1+$ $\left.s C_{1} R_{1}\right)$ and $Z_{2}=\left(s C_{2} R_{2}+1\right) / s C_{2}$, a second-order circuit can be obtained as shown in Figure 3. The current transfer function of Figure 3 is

$$
\frac{I_{\text {out }}}{I_{\text {in }}}=\frac{s^{2} C_{1} C_{2} R_{1} R_{2}+s\left(C_{1} R_{1}+C_{2} R_{2}-2 C_{2} R_{1}\right)+1}{s^{2} C_{1} C_{2} R_{1} R_{2}+s\left(C_{1} R_{1}+C_{2} R_{2}-C_{2} R_{1}\right)+1} .
$$

For $R_{1}=2 R, R_{2}=R$ and $C_{1}=C_{2}=C$, (7) becomes

$$
\frac{I_{\text {out }}}{I_{\text {in }}}=\frac{2 s^{2} C^{2} R^{2}-s C R+1}{2 s^{2} C^{2} R^{2}+s C R+1} .
$$

This represents a second-order allpass function.

For $R_{1}=R_{2}=R$ and $C_{1}=C_{2}=C$, (7) becomes

$$
\frac{I_{\text {out }}}{I_{\text {in }}}=\frac{s^{2} C^{2} R^{2}+1}{s^{2} C^{2} R^{2}+s C R+1} .
$$

This represents a second-order notch function.

In Figure 3, if the $z_{12}$ - output terminal of CCII(1) is eliminated, the transfer function becomes

$$
\frac{I_{\text {out }}}{I_{\text {in }}}=\frac{-s C_{2} R_{1}}{s^{2} C_{1} C_{2} R_{1} R_{2}+s\left(C_{1} R_{1}+C_{2} R_{2}-C_{2} R_{1}\right)+1} .
$$

This represents a second-order bandpass function.

Because the input terminal of Figure 1 is connected directly to the $x$-terminal of CCII(1) and the $y$-terminal of CCII(1) is grounded, the input terminal has the advantage of low input impedance. Because the $I_{\text {out }}$ output terminal is taken out directly from the $z_{12}$ and $z_{22}$ terminals, the $I_{\text {out }}$ output terminal has the advantage of high output impedance. 


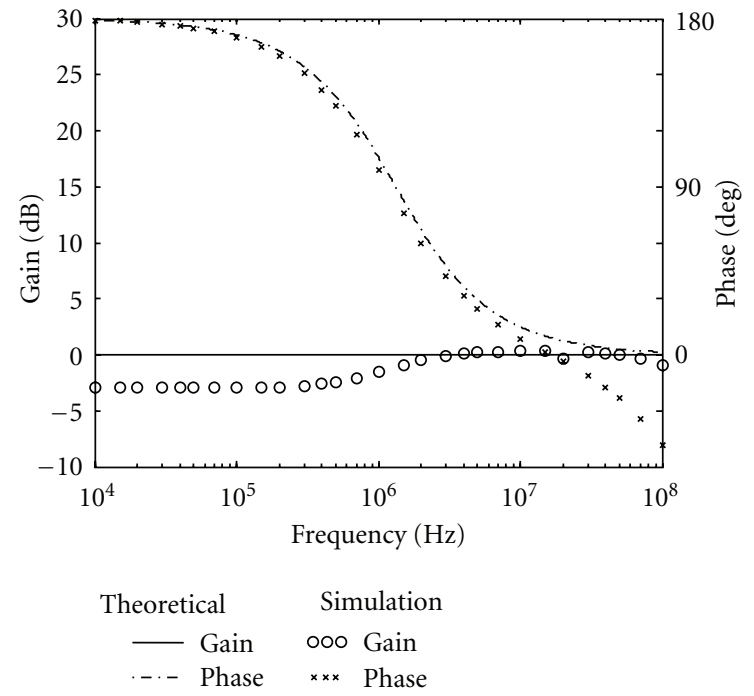

FIGURE 5: Simulation results of the proposed current-mode firstorder allpass filter.

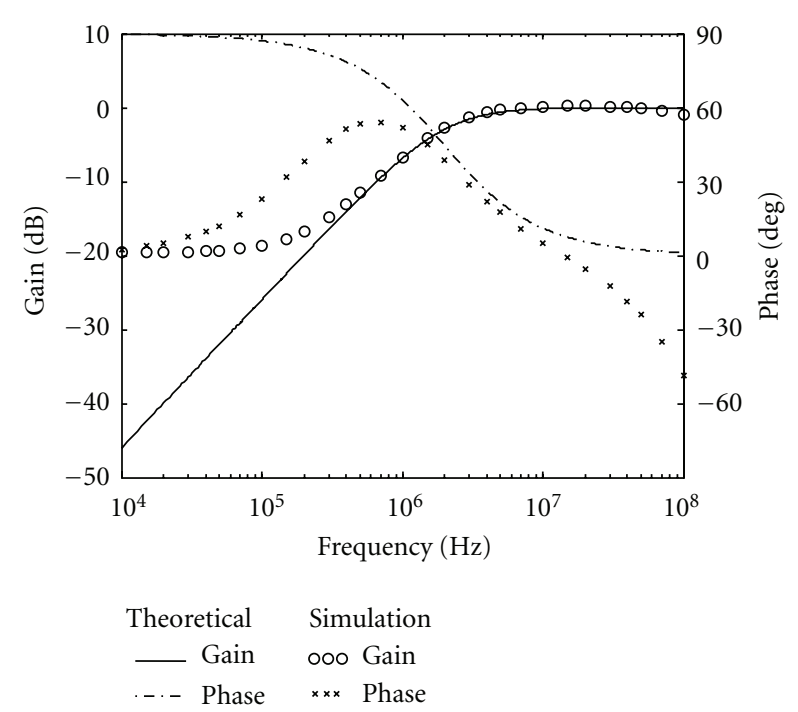

FIGURE 6: Simulation results of the proposed current-mode firstorder highpass filter.

The proposed first-order and second-order filters employ only grounded capacitors. The use of grounded capacitors is attractive for integrated circuit implementation [19].

\section{Nonideality Analysis of the MOCCIIs}

Taking into consideration the MOCCII nonidealities, the port relations of MOCCII can be expressed as

$$
v_{x}=\alpha v_{y}, \quad i_{z}= \pm \beta_{k} i_{x}
$$

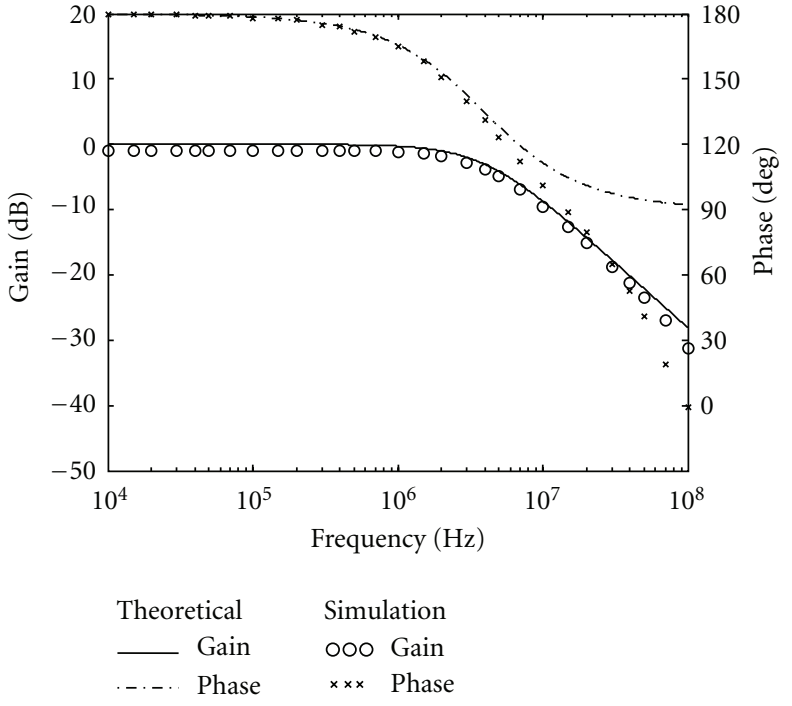

Figure 7: Simulation results of the proposed current-mode firstorder lowpass filter.

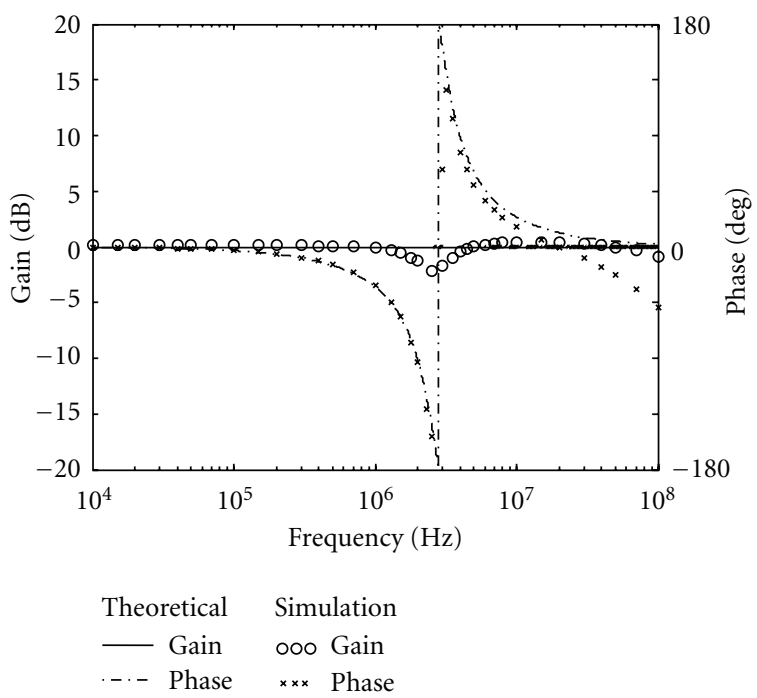

FIGURE 8: Simulation results of the proposed current-mode secondorder allpass filter.

where $\beta_{k}=1-\varepsilon_{k i}$ and $\varepsilon_{k i}\left(\left|\varepsilon_{k i}\right| \ll 1\right)$ denotes the current tracking error, $\alpha=1-\varepsilon_{v}$ and $\varepsilon_{v}\left(\left|\varepsilon_{v}\right| \ll 1\right)$ is the input voltage tracking error of a MOCCII. Reanalysis of the filter circuit in Figure 2 yields the following modified transfer functions:

$$
\frac{I_{\text {out }}}{I_{\text {in }}}=\frac{s C R_{1} R_{2} \beta_{12}+R_{2} \beta_{12}-R_{1} \alpha_{2}\left(\beta_{12} \beta_{21}+\beta_{11} \beta_{22}\right)}{s C R_{1} R_{2}+R_{2}-R_{1} \alpha_{2} \beta_{21}} .
$$

The cutoff angular frequency is obtained by

$$
\omega_{c}=\frac{R_{2}-R_{1} \alpha_{2} \beta_{21}}{C R_{1} R_{2}} .
$$


The active and passive sensitivities are low and obtained as

$$
\begin{aligned}
& S_{C}^{\omega_{c}}=-1, \\
& S_{R_{1}}^{\omega_{c}}=\frac{-R_{2}}{R_{2}-R_{1} \alpha_{2} \beta_{21}}, \\
& S_{R_{2}}^{\omega_{c}}=-S_{\alpha_{2}, \beta_{21}}^{\omega_{c}}
\end{aligned}
$$

$$
=\frac{R_{1} \alpha_{2} \beta_{21}}{R_{2}-R_{1} \alpha_{2} \beta_{21}}
$$

Reanalysis of the filter circuit in Figure 3 yields the following modified transfer functions:

$$
\frac{I_{\text {out }}}{I_{\text {in }}}=\frac{s^{2} C_{1} C_{2} R_{1} R_{2} \beta_{12}+s\left(C_{1} R_{1} \beta_{12}+C_{2} R_{2} \beta_{12}-C_{2} R_{1} \alpha_{2}\left(\beta_{11} \beta_{22}+\beta_{12} \beta_{21}\right)\right)+\beta_{12}}{s^{2} C_{1} C_{2} R_{1} R_{2}+s\left(C_{1} R_{1}+C_{2} R_{2}-C_{2} R_{1} \alpha_{2} \beta_{21}\right)+1} .
$$

The resonance angular frequency and quality factor are obtained by

$$
\begin{gathered}
\omega_{o}=\frac{1}{\sqrt{C_{1} C_{2} R_{1} R_{2}}}, \\
Q=\frac{\sqrt{C_{1} C_{2} R_{1} R_{2}}}{C_{1} R_{1}+C_{2} R_{2}-C_{2} R_{1} \alpha_{2} \beta_{21}} .
\end{gathered}
$$

The active and passive sensitivities are low and obtained as

$$
\begin{aligned}
S_{C_{1}, C_{2}, R_{1}, R_{2}}^{\omega_{o}} & =-\frac{1}{2}, \\
S_{C_{1}}^{Q} & =\frac{-C_{1} R_{1}+C_{2} R_{2}-C_{2} R_{1} \alpha_{2} \beta_{21}}{2\left(C_{1} R_{1}+C_{2} R_{2}-C_{2} R_{1} \alpha_{2} \beta_{21}\right)}, \\
S_{C_{2}}^{Q} & =\frac{C_{1} R_{1}-C_{2} R_{2}+C_{2} R_{1} \alpha_{2} \beta_{21}}{2\left(C_{1} R_{1}+C_{2} R_{2}-C_{2} R_{1} \alpha_{2} \beta_{21}\right)}, \\
S_{R_{1}}^{Q} & =\frac{-C_{1} R_{1}+C_{2} R_{2}+C_{2} R_{1} \alpha_{2} \beta_{21}}{2\left(C_{1} R_{1}+C_{2} R_{2}-C_{2} R_{1} \alpha_{2} \beta_{21}\right)}, \\
S_{R_{2}}^{Q} & =\frac{C_{1} R_{1}-C_{2} R_{2}-C_{2} R_{1} \alpha_{2} \beta_{21}}{2\left(C_{1} R_{1}+C_{2} R_{2}-C_{2} R_{1} \alpha_{2} \beta_{21}\right)}, \\
S_{\alpha_{2}, \beta_{21}}^{Q} & =\frac{C_{2} R_{1} \alpha_{2} \beta_{21}}{C_{1} R_{1}+C_{2} R_{2}-C_{2} R_{1} \alpha_{2} \beta_{21}} .
\end{aligned}
$$

\section{Simulation Results}

HSPICE simulations were carried out to demonstrate the feasibility of the proposed circuits using $0.18 \mu \mathrm{m}$, level 49 MOSFET from TSMC. The MOCCII was realized by the CMOS implementation in Figure 4 [20] with the NMOS and PMOS transistor aspect ratios $W / L=4.5 \mathrm{u} / 0.9 \mathrm{u}$ and $W / L=9 \mathrm{u} / 0.9 \mathrm{u}$, respectively.

Figure 5 represents the magnitude and phase responses of the first-order allpass filter in Figure 2, designed with $f_{c}=1.326 \mathrm{MHz}: C=20 \mathrm{pF}, R_{1}=2 \mathrm{k} \Omega$ and $R_{2}=3 \mathrm{k} \Omega$. The power supply was $\pm 1.25 \mathrm{~V}$. The bias voltage is $V_{b}=-0.6 \mathrm{~V}$. Figure 6 represents the magnitude and phase responses of the first-order highpass filter, designed with $f_{c}=1.989 \mathrm{MHz}$ : $C=20 \mathrm{pF}, R_{1}=2 \mathrm{k} \Omega$, and $R_{2}=4 \mathrm{k} \Omega$. Figure 7 represents the magnitude and phase responses of the first-order lowpass

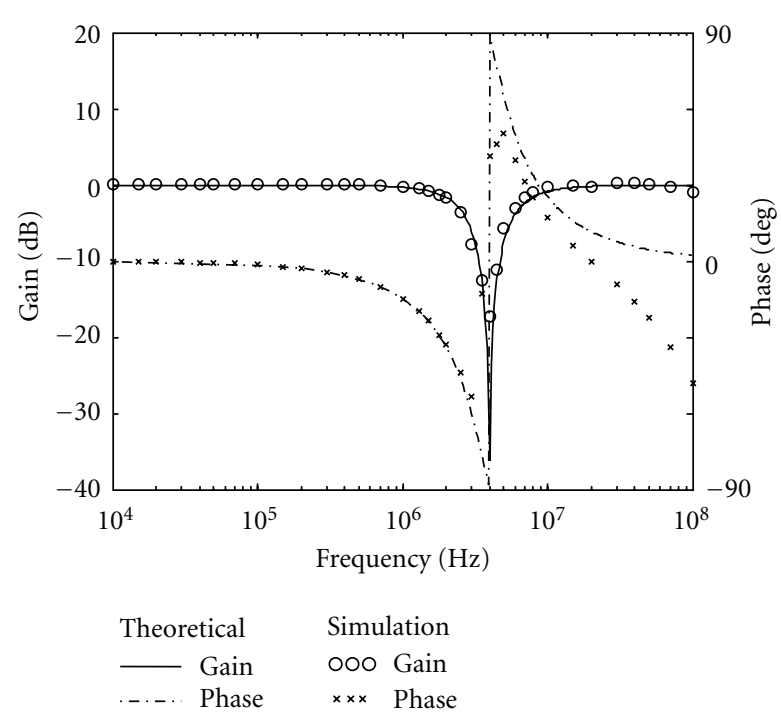

FIGURE 9: Simulation results of the proposed current-mode secondorder notch filter.

filter, designed with $f_{c}=3.979 \mathrm{MHz}: C=20 \mathrm{pF}, R_{1}=1 \mathrm{k} \Omega$, and $R_{2}=2 \mathrm{k} \Omega$.

Figure 8 represents the magnitude and phase responses of the second-order allpass filter in Figure 3, designed with $f_{o}=$ $2.814 \mathrm{MHz}: C_{1}=20 \mathrm{pF}, C_{2}=20 \mathrm{pF}, R_{1}=4 \mathrm{k} \Omega$, and $R_{2}=$ $2 \mathrm{k} \Omega$. Figure 9 represents the magnitude and phase responses of the second-order notch filter, designed with $f_{o}=$ 3.979 MHz: $C_{1}=20 \mathrm{pF}, C_{2}=20 \mathrm{pF}, R_{1}=2 \mathrm{k} \Omega$, and $R_{2}=$ $2 \mathrm{k} \Omega$. Figure 10 represents the magnitude and phase responses of the second-order bandpass filter, designed with $f_{o}=$ $3.979 \mathrm{MHz}: C_{1}=20 \mathrm{pF}, C_{2}=20 \mathrm{pF}, R_{1}=2 \mathrm{k} \Omega$, and $R_{2}=$ $2 \mathrm{k} \Omega$.

A nonideal MOCCII model is shown in Figure 11 [18]. It is shown that the real MOCCII has parasitic resistors and capacitors from the $y$ - and $z$-terminals to the ground, and also, a series resistor at the input terminal $x$. The parasitic resistances of MOCCII become effective at very low frequency. This can explain why Figures 6 and 10 have nonideal frequency responses at low frequencies. Because there are parasitic resistance and capacitance at the output terminal $z$, they introduce a pole at high frequency. This can explain why 


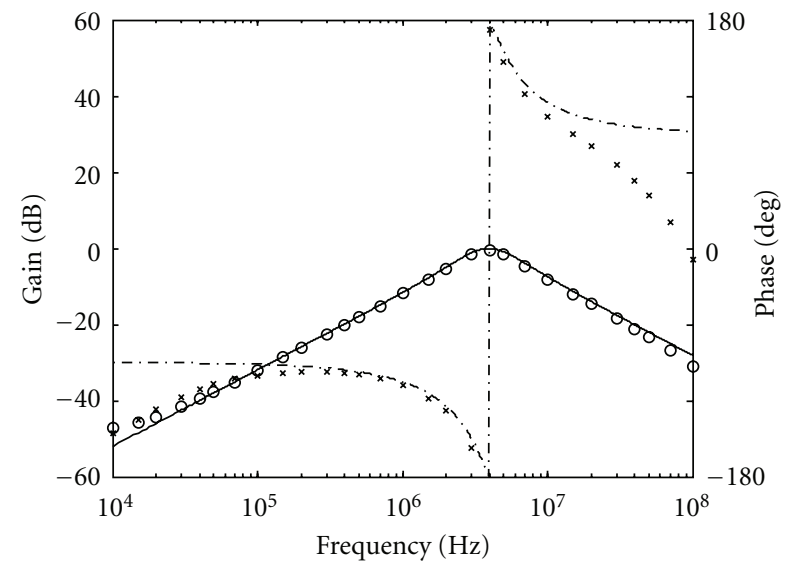

\begin{tabular}{ll} 
Theoretical & \multicolumn{2}{c}{ Simulation } \\
- Gain & ○o Gain \\
$\times \times \times$ Phase
\end{tabular}

Figure 10: Simulation results of the proposed current-mode second-order bandpass filter.

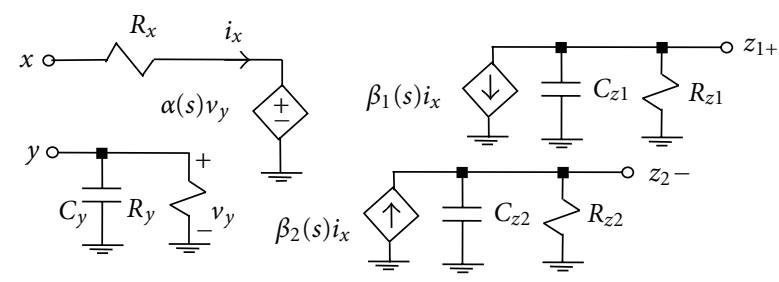

FIGURE 11: The nonideal MOCCII model [18]. $R_{x}=30 \Omega, R_{y}=$ $17 \mathrm{M} \Omega, R_{z 1}=577 \mathrm{k} \Omega, R_{z 2}=572 \mathrm{k} \Omega, C_{y}=1.4 \mathrm{pF}, C_{z 1}=1.2 \mathrm{pF}$, $C_{z 2}=1.2 \mathrm{pF}$.

the simulations have nonideal frequency responses at high frequencies.

\section{Conclusions}

A new cascadable current-mode circuit configuration using two MOCCIIs is presented. The proposed circuit has the advantages of low input and high output impedances. By choosing appropriate passive components, the first-order allpass, lowpass, highpass or second-order allpass, notch, bandpass filters can be obtained. All proposed filters use only grounded capacitors.

\section{Acknowledgment}

The authors would like to thank the reviewers for their suggestions.

\section{References}

[1] C. Toumazou, F. J. Lidgey, and D. G. Haigh, Analog IC Design: The Current-Mode Approach, Peter Peregrinus, London, UK, 1990.
[2] J. W. Horng, "Voltage/current-mode universal biquadratic filter using single CCII+," Indian Journal of Pure and Applied Physics, vol. 48, no. 10, pp. 749-756, 2010.

[3] A. M. Soliman, "Current mode universal filter," Electronics Letters, vol. 31, no. 17, pp. 1420-1421, 1995.

[4] J. W. Horng, "Current-mode and transimpedance-mode universal biquadratic filter using multiple outputs cciis," Indian Journal of Engineering and Materials Sciences, vol. 17, no. 3, pp. 169-174, 2010.

[5] J. W. Horng, C. L. Hou, C. M. Chang, W. Y. Chung, H. L. Liu, and C. T. Lin, "High output impedance current-mode firstorder allpass networks with four grounded components and two CCIIs," International Journal of Electronics, vol. 93, no. 9, pp. 613-621, 2006.

[6] S. Minaei and M. A. Ibrahim, "General configuration for realizing current-mode first-order all-pass filter using DVCC," International Journal of Electronics, vol. 92, no. 6, pp. 347-356, 2005.

[7] S. Maheshwari, "Novel cascadable current-mode first order all-pass sections," International Journal of Electronics, vol. 94, no. 11, pp. 995-1003, 2007.

[8] A. Toker, S. Ozoguz, O. Cicekoglu, and C. Acar, "Currentmode all-pass filters using current differencing buffered amplifier and a new high-Q bandpass filter configuration," IEEE Transactions on Circuits and Systems II: Analog and Digital Signal Processing, vol. 47, no. 9, pp. 949-954, 2000.

[9] S. Kilinç and U. Çam, "Current-mode first-order allpass filter employing single current operational amplifier," Analog Integrated Circuits and Signal Processing, vol. 41, no. 1, pp. 47$53,2004$.

[10] S. Maheshwari, "A new current-mode current-controlled allpass section," Journal of Circuits, Systems and Computers, vol. 16, no. 2, pp. 181-189, 2007.

[11] B. Metin, K. Pal, and O. Cicekoglu, "All-pass filter for rich cascadability options easy IC implementation and tunability," International Journal of Electronics, vol. 94, no. 11, pp. 10371045, 2007.

[12] A. Lahiri and A. Chowdhury, "A novel first-order currentmode all-pass filter using CDTA," Radioengineering, vol. 18, no. 3, pp. 300-305, 2009.

[13] M. Kumngern, W. Jongchanachavawat, and K. Dejhan, "New electronically tunable current-mode universal biquad filter using translinear current conveyors," International Journal of Electronics, vol. 97, no. 5, pp. 511-523, 2010.

[14] A. Ü. Keskin and U. Cam, "Insensitive high-output impedance minimum configuration SITO-type current-mode biquad using dual-output current conveyors and grounded passive components," International Journal of Electronics and Communications, vol. 61, no. 5, pp. 341-344, 2007.

[15] O. Çiçekoğlu, N. Tarim, and H. Kuntman, "Wide dynamic range high output impedance current-mode multifunction filters with dual-output current conveyors," Archiv fur Elektronik und Ubertragungstechnik, vol. 56, no. 1, pp. 55-60, 2002.

[16] J. Zhao, J. G. Jiang, and J. N. Liu, "Design of tunable biquadratic filters employing CCCIIs: state variable block diagram approach," Analog Integrated Circuits and Signal Processing, vol. 62, no. 3, pp. 397-406, 2010.

[17] J.-W. Horng, "Current-mode universal biquadratic filter with five inputs and one output using three ICCIIs," Indian Journal of Pure and Applied Physics, vol. 49, no. 3, pp. 214-217, 2011.

[18] A. Fabre, O. Saaid, and H. Barthelemy, "On the frequency limitations of the circuits based on second generation current conveyors," Analog Integrated Circuits and Signal Processing, vol. 7, no. 2, pp. 113-129, 1995. 
[19] M. Bhushan and R. W. Newcomb, "Grounding of capacitors in integrated circuits," Electronic Letters, vol. 3, no. 4, pp. 148149, 1967.

[20] W. Surakampontorn, V. Riewruja, K. Kumwachara, and K. Dejhan, "Accurate CMOS-based current conveyors," IEEE Transactions on Instrumentation and Measurement, vol. 40, no. 4, pp. 699-702, 1991. 

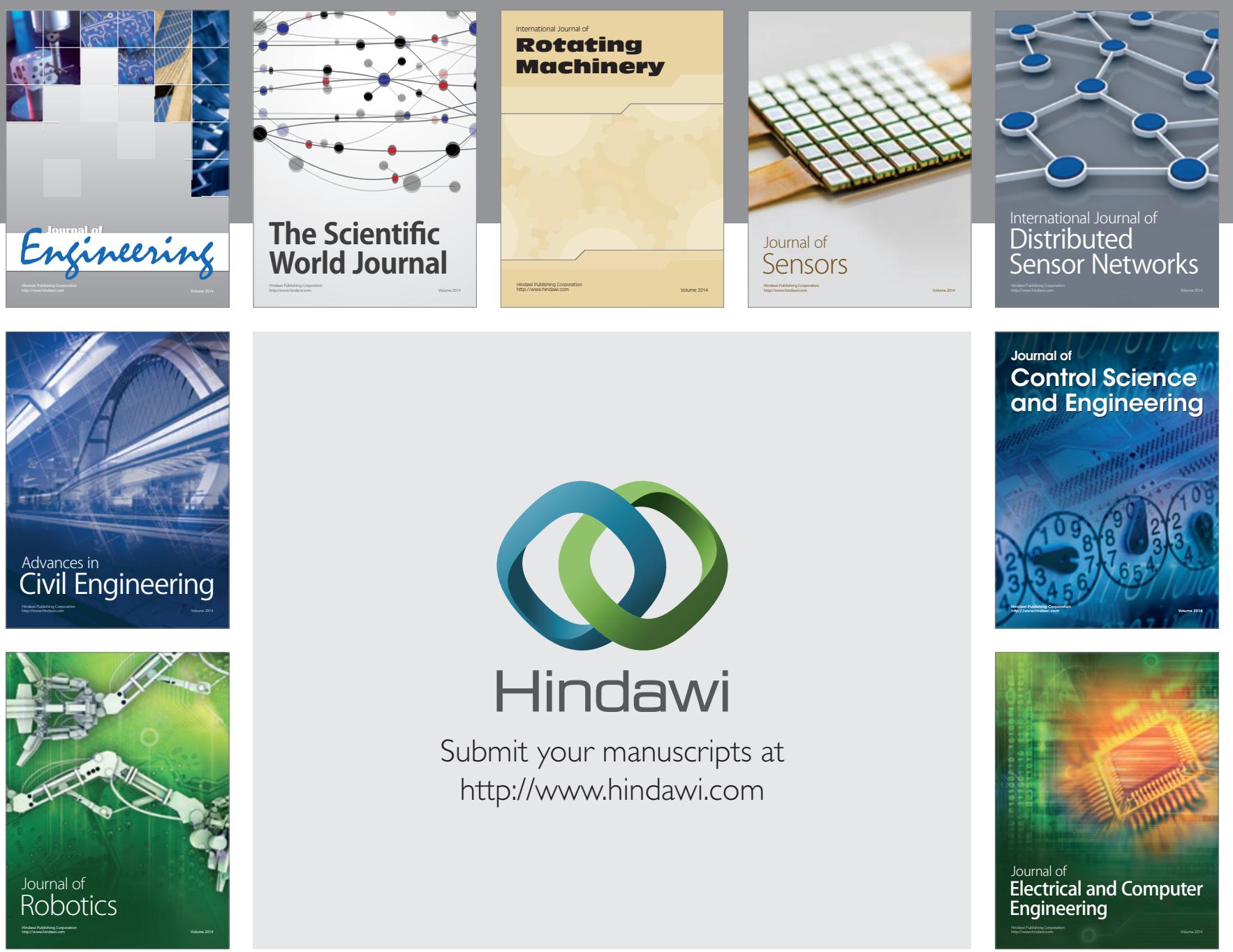

Submit your manuscripts at

http://www.hindawi.com
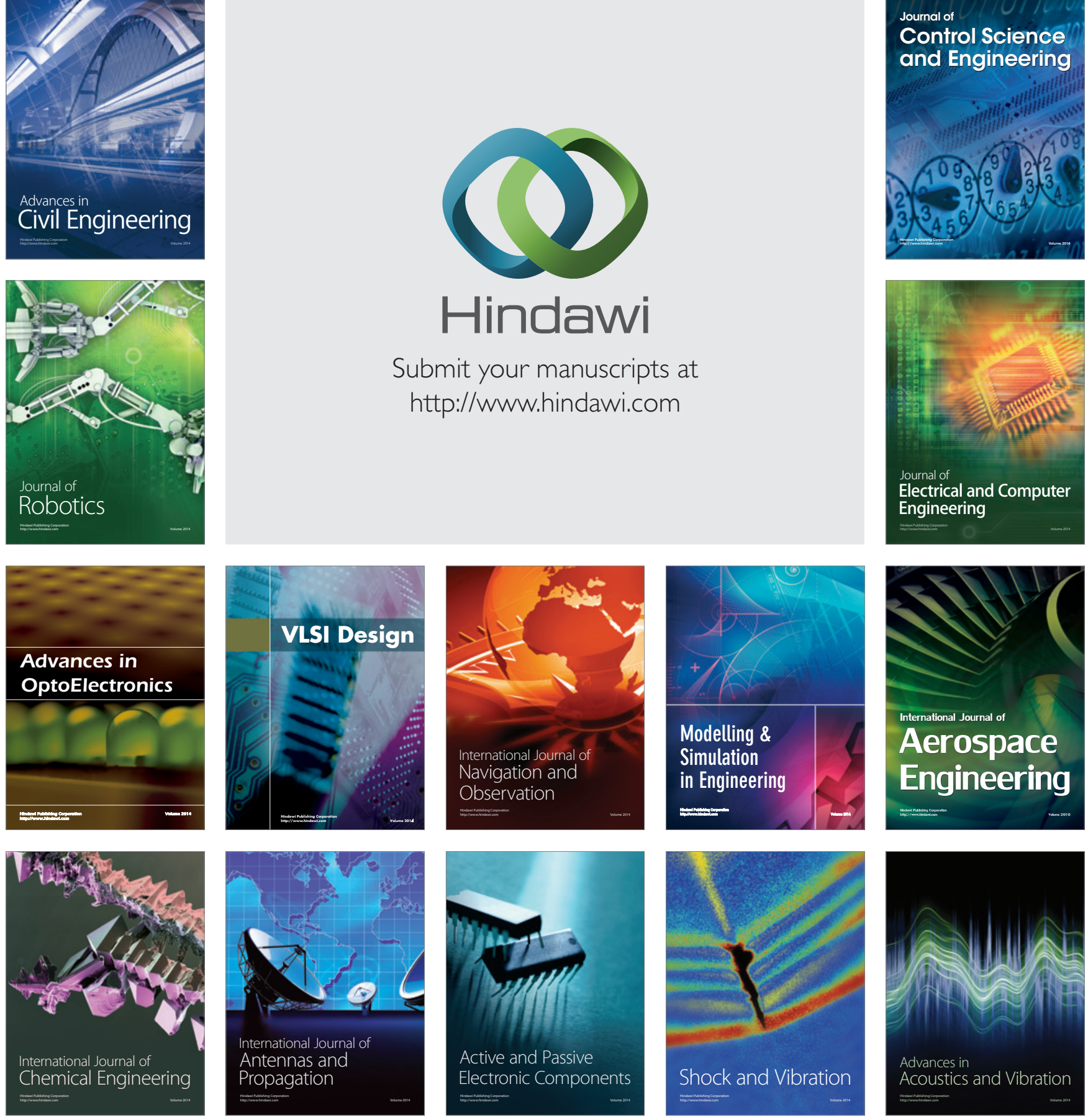